\title{
Management of HCV-Associated Liver Cirrhosis
}

\author{
Maximilian D. Schneider Christoph Sarrazin \\ Medizinische Klinik 1, Universitätsklinikum Frankfurt, Frankfurt/M., Germany
}

Keywords

Hepatitis C virus - Direct-acting antiviral agents .

Liver cirrhosis - Sofosbuvir - Hepatocellular carcinoma

\section{Summary}

Background: Treatment of chronic hepatitis $C$ infection is most urgent in patients with severe liver fibrosis and cirrhosis because of the high risk of decompensation, hepatocellular carcinoma, and consecutively death. The development and approval of several direct-acting antiviral drugs (DAA) in the past years has revolutionized antiviral therapy especially for patients with liver cirrhosis. Methods: This review will focus on recent data from clinical trials and recommendations for the therapy of hepatitis C-infected patients with compensated cirrhosis. Results: Clinical data for cirrhotic patients mainly exist for a combination of the nucleotide analog sofosbuvir with either a protease inhibitor (simeprevir) or an NS5A inhibitor (daclatasvir, ledipasvir) or a three-DAA combination consisting of an NS3 protease inhibitor, an NS5A inhibitor, and a non-nucleoside NS5B inhibitor (paritaprevir/ritonavir, ombitasvir, and dasabuvir). Rates of sustained virologic response in patients with compensated cirrhosis are comparable to patients without cirrhosis; however, the addition of ribavirin and/or longer treatment durations are especially recommended when other negative predictors are present, such as prior treatment failure, features of advanced cirrhosis, or the presence of baseline resistance. Conclusion: Nowadays, a highly active, short, and safe interferon-free treatment regimen is available for almost all patients.

(C) 2016 S. Karger GmbH, Freiburg

\section{Introduction}

Chronic infection with the hepatitis $\mathrm{C}$ virus (HCV) is one of the most common causes of liver cirrhosis and its sequelae in the Western world. Worldwide approximately 130-150 million people are infected. Due to hepatic and extrahepatic diseases, the risk of mortality is significantly increased in patients with HCV infection compared to seronegative persons [1]. A sustained virologic response (SVR) 12-24 weeks after treatment is the goal of antiviral therapy in order to prevent cirrhosis, hepatocellular carcinoma (HCC), and death [2]. Especially in cirrhotic patients, an SVR is associated with a significantly reduced 5-year mortality [3]. However, patients with liver cirrhosis had lower chances of SVR compared to non-cirrhotic patients in the era of pegylated interferon (peginterferon)/ribavirin treatment. Since 2011, antiviral therapy has changed because of the approval of the first direct-acting antiviral agents (DAA), i.e. telaprevir and boceprevir. Administered in combination with peginterferon alpha and ribavirin, these substances increased SVR rates in comparison to the dual combination of peginterferon alpha and ribavirin. However, augmented known and new adverse effects during treatment as well as SVR rates between 19 and $71 \%$ in difficult-to-treat patient groups limited the benefit for patients with cirrhosis [4-7]. Moreover, due to the administration of interferon alpha and the long duration of 48 weeks, the majority of patients with liver cirrhosis had contraindications. The next milestone in antiviral drug development was the approval of sofosbuvir, a nucleotide inhibitor of the HCV polymerase, in 2013/2014. This agent has a high barrier to antiviral drug resistance, rarely causes drugdrug interactions, and has a pan-genotypic efficacy. Therefore, it represents an ideal corner stone as a partner for combination with other DAA which have been approved in 2014, such as the NS3 protease inhibitor simeprevir or the NS5A inhibitors daclatasvir and ledipasvir. These combinations significantly increased SVR rates above $90 \%$ in virtually all groups of patients [8-12]. Comparable results can be achieved with a three-drug regimen containing the NS3 protease inhibitor paritaprevir/ritonavir, the NS5A inhibitor ombitasvir, and the non-nucleoside NS5B inhibitor dasabuvir, which was approved in 2014/2015 [13-16].

\section{KARGER \\ Fax +497614520714

\section{(c) 2016 S. Karger GmbH, Freiburg}

2297-4725/16/0322-0096\$39.50/0
Dr. med. Maximilian David Schneider 
Table 1. Available and approved substances for HCV treatment in the Western world

Pegylated interferon alpha $2 \mathrm{a}$ and $2 \mathrm{~b}$
Ribavirin
NS3/4A protease inhibitors
First wave (associated with numerous side effects and high pill burden)
Telaprevir
Boceprevir
Second wave (improved tolerability and once-daily dosing)
$\quad$ Simeprevir
$\quad$ Paritaprevir (ritonavir-boosted)
NS5A inhibitors
Daclatasvir
Ledipasvir
Ombitasvir
Nucleotide NS5B polymerase inhibitor
Sofosbuvir
Non-nucleoside NS5B polymerase inhibitor
Dasabuvir

The substances which are currently available and approved for HCV treatment in the Western world are shown in table 1.

\section{General Aspects}

Prior to antiviral therapy, every patient needs a workup for coexisting liver diseases, especially viral hepatitis B and HIV infection as well as non-alcoholic or alcoholic steatohepatitis. The severity of liver disease is mainly represented by the stage of liver fibrosis, which has to be assessed when definite symptoms or signs of liver cirrhosis are missing. Non-invasive techniques for the assessment of liver fibrosis are well evaluated in chronic hepatitis C. Transient elastography is the most commonly used ultrasound-based technique. The correlation between liver stiffness measurements, e.g. by FibroScan ${ }^{\mathrm{TM}}$ or $\mathrm{ARFI}^{\mathrm{TM}}$, and fibrosis staging is good for the diagnosis of significant fibrosis and excellent for the diagnosis of liver cirrhosis $[17,18]$. Non-invasive biomarkers (e.g. APRI, Fibrotest $^{\mathrm{TM}}$, Fibromax ${ }^{\mathrm{TM}}$, Fibrosure ${ }^{\mathrm{TM}}$ ) for the quantification of liver fibrosis can be alternatively used when elastography is not available. A combination of both methods has been shown to improve accuracy and to reduce the number of liver biopsies in undistinguishable cases [19].

When chronic HCV infection exists, antiviral therapy should always be considered. According to the European Association for the Study of the Liver (EASL) as well as German guidelines, antiviral therapy can be prioritized for patients with significant fibrosis and cirrhosis because of high costs of antiviral treatment and limited capacities of health care systems [20,21].

Prior to treatment, cirrhotic patients should be screened for esophageal varices, HCC, and signs of hepatic decompensation, such as hepatic encephalopathy, ascites, and infectious problems. In general, the chance of achieving SVR with DAA combination regimens in patients with compensated cirrhosis (Child-Pugh A) is comparable to non-cirrhotic patients; however, there is a remaining risk for decompensation and acute-on-chronic liver failure during and after treatment [22]. Patients with advanced and decompensated cirrhosis should be treated in experienced centers, and the need for liver transplantation should be evaluated. In patients with end-stage liver disease and high short-term mortality, no clinical improvement might be visible despite viral eradication [23-25]. These patients may have a greater benefit from antiviral therapy after liver transplantation.

\section{Antiviral Therapy}

The decision for or against a certain antiviral treatment regimen depends on several factors. Firstly, the HCV genotype has to be determined. The majority of available DAA combination regimens are active against HCV genotype 1 but differ in their activity against other HCV genotypes and subtypes. Secondly, prior antiviral therapies have to be considered. Patients with a relapse or nonresponse after treatment with peginterferon and ribavirin still have high chances of viral eradication. However, prior treatments with DAA may be associated with the selection of resistance-associated variants (RAV) which may influence treatment outcome of subsequent DAA combination regimens. Here, resistance analysis is recommended for the selection of an effective DAA combination, if available. Thirdly, the viral load in international units quantified via real-time polymerase chain reaction (PCR) is of importance prior to the beginning of treatment, when a short therapy over 8 weeks in patients without cirrhosis is considered. Forthly, concomitant medications have to be checked for potential drug-drug interactions (www.hep-druginteractions.org).

Due to the short duration, improved tolerability and high efficacy as well as potential long-lasting side effects, interferon-free HCV treatment is the preferred recommendation [20, 21]. Nevertheless, in countries with restricted access to new antivirals, interferon-containing regimens can still be an option.

The indication for HCV treatment in HCV/HIV co-infected patients is identical to those in patients with HCV monoinfection. In general, the fibrosis progression in patients co-infected with HIV is accelerated. Several trials were conducted in co-infected patients, and the treatment outcomes were comparable to patients with monoinfection [26-29]. Some antiretroviral agents and combinations were co-administered in clinical trials. Therefore, potential drugdrug interactions have to be considered prior to treatment.

Table 2 gives an overview about the recommended and approved treatment options for the different genotypes for patients with cirrhosis. The corresponding SVR rates are illustrated in table 3 .

In the following part of the review, the recommended antiviral therapies for patients with compensated cirrhosis are presented. HCV therapy for patients with decompensated cirrhosis is discussed by Welker and Zeuzem [30] in a separate article in this special issue. 
Table 2. Treatment recommendations according to the different genotypes for patients with cirrhosis

\begin{tabular}{|c|c|c|c|}
\hline Treatment combination & Duration, weeks & TN & $\mathrm{TE}$ \\
\hline \multicolumn{4}{|l|}{ Genotype 1} \\
\hline $\mathrm{SOF}+\mathrm{SMV} \pm \mathrm{R}$ & 12 or 24 & app & app \\
\hline $\mathrm{SOF}+\mathrm{DCV} \pm \mathrm{R}$ & 12 or 24 & app & app \\
\hline SOF + LDV & 12 & app & nrec \\
\hline $\mathrm{SOF}+\mathrm{LDV}+\mathrm{R}$ & 12 & rec & rec \\
\hline SOF + LDV & 24 & rec & rec \\
\hline $\mathrm{SOF}+\mathrm{LDV}+\mathrm{R}$ & 24 & app & app \\
\hline $\mathrm{PTV} / \mathrm{r}+\mathrm{OMV}+\mathrm{DSV}$ & 12 & app (1b) & app (1b) \\
\hline $\mathrm{PTV} / \mathrm{r}+\mathrm{OMV}+\mathrm{DSV}+\mathrm{R}$ & 12 & $\operatorname{rec}(1 b)$ & $\operatorname{rec}(1 b)$ \\
\hline $\mathrm{PTV} / \mathrm{r}+\mathrm{OMV}+\mathrm{DSV}+\mathrm{R}$ & 24 & $\operatorname{rec}(1 a)$ & $\operatorname{rec}(1 \mathrm{a})$ \\
\hline \multicolumn{4}{|l|}{ Genotype 2} \\
\hline $\mathrm{SOF}+\mathrm{R}$ & 12 & rec & rec (16-24 weeks) \\
\hline $\mathrm{SOF}+\mathrm{P} / \mathrm{R}$ & 12 & app & app \\
\hline $\mathrm{SOF}+\mathrm{DCV} \pm \mathrm{R}$ & 12 & nrec & app \\
\hline \multicolumn{4}{|l|}{ Genotype 3} \\
\hline $\mathrm{SOF}+\mathrm{R}$ & 24 & rec & app \\
\hline $\mathrm{SOF}+\mathrm{P} / \mathrm{R}$ & 12 & app & app \\
\hline $\mathrm{SOF}+\mathrm{DCV}+\mathrm{R}$ & 24 & app & rec \\
\hline \multicolumn{4}{|l|}{ Genotype 4} \\
\hline $\mathrm{SOF}+\mathrm{LDV}+\mathrm{R}$ & 12 & rec & rec \\
\hline $\mathrm{SOF}+\mathrm{LDV} \pm \mathrm{R}$ & 24 & app & app \\
\hline $\mathrm{PTV} / \mathrm{r}+\mathrm{OMV}+\mathrm{R}$ & 24 & app & app \\
\hline $\mathrm{SOF}+\mathrm{SMV} \pm \mathrm{R}$ & 12 & app & app \\
\hline
\end{tabular}

Table 3. SVR rates

for the different

treatment options in hepatitis $\mathrm{C}$ patients with (mainly compensated) cirrhosis

\begin{tabular}{|c|c|c|c|c|c|}
\hline \multirow[t]{2}{*}{ Treatment combination } & \multirow{2}{*}{$\begin{array}{l}\text { Duration, } \\
\text { weeks }\end{array}$} & \multicolumn{4}{|l|}{ Genotype } \\
\hline & & 1 & 2 & 3 & 4 \\
\hline $\mathrm{SOF}+\mathrm{R}$ & 12 & & 83-94 (TN) & 34 & 43 \\
\hline $\mathrm{SOF}+\mathrm{R}$ & 16 & & 87 & & \\
\hline $\mathrm{SOF}+\mathrm{R}$ & 24 & & 100 & 60 (TE)-92 (TN) & 100 \\
\hline $\mathrm{SOF}+\mathrm{SMV} \pm \mathrm{R}$ & $12 / 24$ & 83 (w/o R) & & & 100 \\
\hline $\mathrm{SOF}+\mathrm{DCV} \pm \mathrm{R}$ & 12 & 92 & & $83-89$ & \\
\hline $\mathrm{SOF}+\mathrm{DCV} \pm \mathrm{R}$ & 24 & 97 & & & \\
\hline $\mathrm{SOF}+\mathrm{LDV}+\mathrm{R}$ & 12 & 96 & & & \\
\hline $\mathrm{SOF}+\mathrm{LDV}$ & 24 & 98 & & & $93-96$ \\
\hline $\mathrm{SOF}+\mathrm{LDV}+\mathrm{R}$ & 24 & 100 & & & \\
\hline $\mathrm{PTV} / \mathrm{r}+\mathrm{OMV}+\mathrm{DSV}$ & 12 & $100(1 b)$ & & & \\
\hline $\mathrm{PTV} / \mathrm{r}+\mathrm{OMV}+\mathrm{DSV}+\mathrm{R}$ & 12 & 92 & & & \\
\hline $\mathrm{PTV} / \mathrm{r}+\mathrm{OMV}+\mathrm{DSV}+\mathrm{R}$ & 24 & 96 & & & \\
\hline $\mathrm{PTV} / \mathrm{r}+\mathrm{OMV}+\mathrm{R}$ & $12 / 24$ & & & & $96-100$ \\
\hline
\end{tabular}

$\mathrm{TN}=$ Treatment-naïve; $\mathrm{TE}$ = treatment-experienced; $\mathrm{SOF}=$ sofosbuvir; $\mathrm{SMV}=$ simeprevir; $\mathrm{R}$ = ribavirin; $\mathrm{DCV}=$ daclatasvir; $\mathrm{LDV}=$ ledipasvir; $\mathrm{PTV} / \mathrm{r}=$ paritaprevir/ritonavir; $\mathrm{OMV}=$ ombitasvir; $\mathrm{DSV}=$ dasabuvir.

\section{Genotype 1}

\section{Ledipasvir + Sofosbuvir \pm Ribavirin}

The combination of the nucleotide HCV polymerase inhibitor sofosbuvir and ledipasvir, an NS5A inhibitor, has been evaluated in a broad phase III study program (ION studies) and has shown consistently high rates of sustained response in all groups of patients, including those with failure to boceprevir or telaprevir pre-treatment $(>90 \%)$. This combination treatment is available as a fixeddose formulation (400 mg sofosbuvir + $90 \mathrm{mg}$ ledipasvir). An anal- 
ysis of all cirrhotic patients treated in phase II and III studies ( $\mathrm{n}>$ 500) demonstrated SVR rates of $92,96,98$, and $100 \%$ for ledipasvir/ sofosbuvir 12 weeks, ledipasvir/sofosbuvir + ribavirin 12 weeks, ledipasvir/sofosbuvir 24 weeks, and ledipasvir/sofosbuvir + ribavirin, respectively. The overall SVR rates were significantly lower in treatment-experienced patients with a platelet count $<75,000 / \mu \mathrm{l}$ (82\%) [31]. The SIRIUS trial prospectively evaluated ledipasvir/sofosbuvir + ribavirin for 12 weeks and ledipasvir/sofosbuvir + placebo for 24 weeks and found similar rates of SVR (96 and 97\%) [32]. Thus, in order to reduce costs and duration of antiviral therapy, the EASL and the German guidelines recommend ledipasvir/ sofosbuvir + ribavirin for 12 weeks as the favored option in patients with compensated cirrhosis. Due to an SVR rate of $96 \%$ with 12 weeks of sofosbuvir and ledipasvir in treatment-naïve patients with cirrhosis, a ribavirin-free treatment is also an option. A longer duration of therapy can be considered when contraindications, intolerance to ribavirin, or negative predictors of a successful treatment outcome exist $[20,21]$.

\section{Paritaprevir/Ritonavir + Ombitasvir + Dasabuvir + Ribavirin}

The TURQUOISE-II trial was a phase III study evaluating paritaprevir/ritonavir + ombitasvir + dasabuvir + ribavirin over 12 or 24 weeks in patients with compensated cirrhosis. SVR rates were 92 and $96 \%$ for 12 and 24 weeks, respectively. Throughout all phase III studies the regimen showed higher efficacy in patients infected with HCV-subtype $1 \mathrm{~b}$ compared to subtype 1a. Retrospective analysis showed reduced SVR rates in the 12-week treatment arm only in a subgroup of HCV genotype la-infected patients. Treatment failures in HCV genotype la-infected patients in the 12-week group were associated with an alpha-fetoprotein level $>20 \mathrm{ng} / \mathrm{ml}$, a platelet count $<90,000 / \mu \mathrm{l}$, or an albumin level $<35 \mathrm{~g} / \mathrm{l}$ [15]. Therefore, paritaprevir/ritonavir + ombitasvir + dasabuvir + ribavirin should be administered as a standard treatment for all HCV genotype 1 -infected patients with cirrhosis for 12 weeks, with the exception of HCV genotype 1a-infected patients with one of the negative predictive laboratory values mentioned above. In this case a treatment duration of 24 weeks is recommended. More recently, paritaprevir/ritonavir + ombitasvir + dasabuvir were investigated without ribavirin in patients with compensated cirrhosis and genotype $1 \mathrm{~b}$ infection in a single-arm non-controlled study (TURQUOISE III) for 12 weeks. Based on an SVR rate of 100\% [33], the ribavirinfree regimen can be recommended as a new standard treatment in this population.

Generally, there are no differences in antiviral efficacy for treatment-naive versus experienced patients. However, patients with failure to boceprevir or telaprevir triple therapies have not been studied, and currently it is unknown whether selection of viral resistance to NS3 protease inhibitors may impact treatment outcome.

The combination of paritaprevir/ritonavir + ombitasvir + dasabuvir should not be administered to patients with decompensated cirrhosis (Child-Pugh B or C) due to an observed increased rate of hepatic failure and decompensation in these patients.

\section{Sofosbuvir + Simeprevir + Ribavirin}

In cohort 2 of the COSMOS study, the combination of simeprevir with sofosbuvir was evaluated in treatment-naive patients and previous non-responders to peginterferon and ribavirin with advanced fibrosis or cirrhosis (METAVIR F3-4). Patients were assigned to 12 or 24 weeks of treatment either with or without ribavirin. In cohort 2, 93-100\% SVR rates were achieved, and there were no beneficial effects of additional ribavirin or longer treatment durations [11]. Cirrhotic patients (treatment-naïve and peginterferon/ribavirin-experienced) had an SVR rate of $83 \%$ with sofosbuvir + simeprevir over 12 weeks in the OPTIMIST-2 study [25]. In both studies, patients with virological relapse after treatment were in the majority genotype 1a patients, and the RAV Q80K was found at baseline (SVR 74 vs. 92\% with and without Q80K mutation, respectively). Therefore, a resistance analysis can be useful in genotype 1a patients when a simeprevir-containing treatment is considered, especially when a protease inhibitor was given earlier.

\section{Sofosbuvir + Daclatasvir + Ribavirin}

The ALLY-1 study evaluated the treatment of sofosbuvir + daclatasvir + ribavirin over 12 weeks in cirrhotic patients (ChildPugh A-C) as well as after liver transplantation and HCV recurrence. Patients with compensated cirrhosis achieved an SVR in $92 \%$ of cases [24]. Before the approval of the two components, a compassionate use program treated mainly cirrhotics with sofosbuvir + daclatasvir with and without ribavirin for 24 weeks. In this difficult-to-treat population high SVR rates were found ( $97 \%$ for patients with liver cirrhosis), but the numbers of patients with only 12 weeks of therapy were low [34]. The EASL guidelines favor a 12week therapy with ribavirin in cirrhotic patients. When ribavirin is contraindicated, a treatment duration of 24 weeks is recommended.

\section{Genotype 2}

\section{Sofosbuvir + Ribavirin}

This treatment option was evaluated during several phase III trials in patients with genotype 2 infection. Patients with cirrhosis had lower SVR rates than patients without cirrhosis after 12 weeks of treatment (92-97 vs. 83-94\%), but the numbers of cirrhotic patients were low ( $\mathrm{n}=12$ and 17$)[35,36]$. In previous interferon relapsers and non-responders with genotype 2 and cirrhosis, only 6 of 10 patients achieved SVR with this combination [36]. Realworld studies after approval in cirrhotic genotype 2 patients showed similar results with a 12-week treatment course (SVR 76$82 \%)[37,38]$. Therefore, a longer treatment duration was evaluated in the BOSON study: Cirrhotic genotype 2 patients achieved 87 and 100\% SVR rates with 16 and 24 weeks of sofosbuvir + ribavirin, respectively [39]. To date, this data has not been implemented in current guidelines.

The analysis of treatment failures in genotype 2 after sofosbuvir + ribavirin treatment illustrated the possible existence of intergenotypic recombinant hepatitis $\mathrm{C}$ viruses. In these cases, viral chimera of genotype 1 and 2 are identified as genotype 2 via the com- 
monly used INNO-LiPA 2.0 assay, but their treatment responses were comparable to genotype 1 patients [40].

Most recently, results of a phase III study with the combination of sofosbuvir and the new NS5A inhibitor velpatasvir with high antiviral activity in HCV genotype 2 have been presented. All (19/19) patients with cirrhosis and genotype 2 infection achieved an SVR. However, the compared treatment sofosbuvir + ribavirin over 24 weeks also showed an SVR in 18/19 patients in this study [41].

\section{Sofosbuvir + Daclatasvir \pm Ribavirin}

No systematically evaluated data exist for genotype 2 patients with cirrhosis for this treatment option. However, daclatasvir showed high antiviral efficacy in HCV genotype 2 isolates in vitro $[42,43]$, and its theoretical potency was demonstrated in a small phase II trial in patients without cirrhosis (SVR 96\%) [12]. In genotype 2 , this treatment should be reserved for patients who failed the standard treatment, i.e. sofosbuvir + ribavirin.

\section{Genotype 3}

\section{Sofosbuvir + Ribavirin}

In genotype 3 patients, rates of SVR were disappointing with 12 weeks of treatment, especially in patients with cirrhosis (SVR 34\%) [35]. A treatment expansion up to 24 weeks demonstrated an improvement with $82-92 \%$ SVR in treatment-naïve cirrhotic patients, but only $60-76 \%$ SVR in patients with liver cirrhosis and failure to prior peginterferon/ribavirin $[39,44]$. Similar results have been obtained from real-world studies [37].

\section{Sofosbuvir + Pegylated Interferon Alpha + Ribavirin}

In the BOSON study, the expanded treatment with sofosbuvir + ribavirin was compared to a conventional triple therapy including peginterferon alpha. This treatment was significantly superior compared to sofosbuvir + ribavirin over 24 weeks alone (SVR 88 vs. 79\%) [39]. Thus, peginterferon in combination with sofosbuvir and ribavirin remains a treatment option especially in difficult-totreat genotype 3 patients who are interferon-tolerant.

\section{Sofosbuvir + Daclatasvir \pm Ribavirin}

In contrast to patients without cirrhosis, sofosbuvir + daclatasvir therapy over 12 weeks demonstrated an SVR in only $63 \%$ of patients with cirrhosis [45]. Therefore, the ALLY3+ study compared sofosbuvir + daclatasvir + ribavirin for 12 and 16 weeks in patients with advanced fibrosis and compensated cirrhosis. SVR rates were comparable: Patients with cirrhosis achieved an SVR in $15 / 18$ patients $(83 \%)$ and $16 / 18$ patients $(89 \%)$ in the 12 -week and 16-week treatment arm, respectively. Both relapsers in the 16-week group were sofosbuvir-experienced [46]. Meanwhile, data from a European compassionate use program are available: Genotype 3 patients with an urgent need for antiviral therapy were treated in most cases with sofosbuvir + daclatasvir with or without ribavirin for 24 weeks. SVR rates were $87 \%$, with the highest rates being found in compensated cirrhotics. The use of ribavirin was not associated with higher SVR rates; however, SVR rates were lower in a minority of patients who received therapy for 12 weeks only [47]. Because of missing alternative treatment options guidelines recommend a treatment expansion with the addition of ribavirin and a duration of 24 weeks.

Also in genotype 3, velpatasvir + sofosbuvir over 12 weeks demonstrated significantly higher SVR rates compared to sofosbuvir + ribavirin over 24 weeks (cirrhotics 91 vs. 66\%) and will expand the treatment options for genotype 3 patients after approval (expected in 2016) [41].

\section{Genotype 4}

\section{Ledipasvir + Sofosbuvir \pm Ribavirin}

In a small trial ( $\mathrm{n}=21$ patients), ledipasvir/sofosbuvir for 12 weeks was evaluated in genotype 4 and achieved an SVR in 7/7 patients with cirrhosis [48]. Another study included 44 genotype 4 patients and demonstrated high SVR rates (93\%) irrespective of prior treatment or fibrosis status [49]. Similar to the treatment in genotype 1 patients, current guidelines recommend ledipasvir/sofosbuvir and ribavirin for 12 weeks in case of underlying cirrhosis until further data is available.

\section{Paritaprevir/Ritonavir + Ombitasvir \pm Ribavirin}

Dasabuvir has no significant antiviral activity in genotype 4; therefore, treatment with paritaprevir/ritonavir and ombitasvir is sufficient. In a recently published study, paritaprevir/ritonavir + ombitasvir + ribavirin was compared for 12 and 16 weeks in patients with cirrhosis. In both groups high SVR rates were achieved (96 and $100 \%$ for 12 and 16 weeks, respectively) [50]. The combination is approved for a 24 -week treatment with ribavirin in patients with cirrhosis.

\section{Simeprevir + Sofosbuvir}

Recently, data from an Egyptian study were published. Genotype 4 patients with cirrhosis $(n=23)$ were treated with simeprevir + sofosbuvir for 12 weeks and achieved an SVR in all cases [51].

\section{Genotype 5 \& 6}

Compared to HCV genotype 1-4, patients infected with $\mathrm{HCV}$ genotypes 5 and 6 are uncommon in the Western world. In a small trial, 8/9 cirrhotic HCV genotype 5 patients achieved an SVR with ledipasvir/sofosbuvir over 12 weeks [49]. Similar results were found in a trial with HCV genotype 6 patients (SVR 96\%, only 2 patients with cirrhosis) [52].

Based on data of patients infected with genotype 1, cirrhotic patients should be treated with ledipasvir/sofosbuvir for 12 weeks and additional ribavirin, although this regimen is not formally approved for the use in patients infected with HCV genotype 5 or 6 . 


\section{Safety Aspects and Adverse Effects of Antivirals}

\section{Sofosbuvir}

Sofosbuvir is generally well tolerated. Common side effects are nausea and sleep disturbances. Severe and life-threatening bradycardias were observed in combination with amiodarone. As a result, these agents must not be co-administered.

\section{Sofosbuvir + Ledipasvir}

Ledipasvir was investigated in combination with sofosbuvir only. Adverse events were tiredness and headache. Less than $2 \%$ of cirrhotic patients had serious adverse events during phase III studies [31]. Interestingly, the TARGET study showed a difference in SVR rates in patients who had a co-medication with a proton pump inhibitor (98 without vs. $93 \%$ with proton pump inhibitor) [53]. When possible, a co-administration should be avoided.

\section{Simeprevir}

Beside nausea, headache, and tiredness, a photosensitivity reaction of the skin can occasionally be present during treatment. It is important to inform the patient about limiting sun exposure and using sun protection. A hyperbilirubinemia is a common finding. In most cases it is mild, and severe hyperbilirubinemia was seen in $<1 \%$ of cases.

\section{Daclatasvir}

The safety profile of daclatasvir is comparable to the other new DAA. Headache, fatigue, and nausea are the most common side effects during treatment.

\section{Paritaprevir/Ritonavir + Ombitasvir + Dasabuvir}

The most common adverse events found during approval studies were sleep disturbances, nausea, and itching. Elevations of bilirubin to more than three times the upper limit of normal were more often seen in cirrhotics (9.7\%); relevant elevations of alanine aminotransferase were less common. Due to these possible hepatotoxic effects and an observed worsening of liver function in several patients with decompensated cirrhosis, this treatment cannot be recommended for decompensated patients.

\section{Ribavirin}

In several treatment combinations for patients with cirrhosis ribavirin is still mandatory. Its adverse effect profile is mainly caused by hemolytic anemia. Dose adjustments during therapy can be required for the management of anemia. Common symptoms are dyspnea, fatigue, and cough.

\section{Surveillance and Follow-up after SVR}

An SVR 12 weeks after the end of therapy is associated with a long-lasting cure in more than $99 \%$ of patients. An additional PCR testing 24 or 48 weeks after therapy can be performed although upon detectable HCV RNA at this time point, further analysis for assessment of late relapse versus re-infection should always be initiated. In patients with cirrhosis despite SVR, a significant risk for the development of HCC, cholangiocarcinoma, and hepatic decompensation is still present, and long-term surveillance is mandatory for years. However, patients with viral eradication showed a significant risk reduction in comparison to those without SVR [54]. After SVR an improvement of liver stiffness measurement values was observed with transient elastography, indicating a regression of fibrosis in the long-term follow-up [55]. Co-factors which can cause fibrosis progression, such as alcohol consumption and diabetes, have to be avoided. In cirrhotic patients, a regular surveillance for HCC by abdominal ultrasound and an alpha-fetoprotein measurement every 6 months is recommended. The occurrence of esophageal varices after SVR is rare if varices were not present at pre-treatment endoscopy. After SVR, an endoscopic control for varices is recommended every 2 years after SVR [56]. Invasive measurements of hepatic venous pressure gradients before and after antiviral treatment showed a significant reduction after SVR, indicating a regression and partial normalization in most patients with portal hypertension [57].

\section{Disclosure Statement}

M.D. Schneider: No disclosures.

C. Sarrazin: Consultancies/Advisory boards: Abbott, Abbvie, BMS, Gilead, Janssen, Merck/MSD, and Roche. Research support: Abbott, Gilead, Janssen, Qiagen, Roche, and Siemens. Speaker: Abbott, Abbvie, Achillion, BMS, Gilead, Janssen, Merck/MSD, Qiagen, Roche, and Siemens.

\section{References}

$>_{1}$ Lee MH, Yang HI, Lu SN, Jen CL, You SL, Wang LY, Wang CH, Chen WJ, Chen CJ: Chronic hepatitis C virus infection increases mortality from hepatic and extrahepatic diseases: a community-based long-term prospective study. J Infect Dis 2012;206:469-477.
2 Hill AM, Saleem J, Heath KA, Simmons B: Effects of sustained virological response (SVR) on the risk of liver transplant, hepatocellular carcinoma, death and re-infection: meta-analysis of 129 studies in 23,309 patients with hepatitis c infection. Hepatology 2014;60: 218A-219A.
Simmons B, Saleem J, Heath K, Cooke GS, Hill A: Long-term treatment outcomes of patients infected with hepatitis c virus: a systematic review and metaanalysis of the survival benefit of achieving a sustained virological response. Clin Infect Dis 2015;61:730-740. 
4 Sherman KE, Flamm SL, Afdhal NH, Nelson DR, Sulkowski MS, Everson GT, Fried MW, Adler M, Reesink HW, Martin M, Sankoh AJ, Adda N, Kauffman RS, George S, Wright CI, Poordad F: Response-guided telaprevir combination treatment for hepatitis $\mathrm{C}$ virus infection. N Engl J Med 2011;365:1014-1024.

5 Zeuzem S, Andreone P, Pol S, et al: Telaprevir for retreatment of HCV infection. N Engl J Med 2011;364: 2417-2428.

6 Bacon BR, Gordon SC, Lawitz E, Marcellin P, Vierling JM, Zeuzem S, Poordad F, Goodman ZD, Sings HL, Boparai N, Burroughs M, Brass CA, Albrecht JK, Esteban R; HCV RESPOND-2 Investigators: Boceprevir for previously treated chronic HCV genotype 1 infection. N Engl J Med 2011;364:1207-1217.

7 Poordad F, McCone J, Bacon BR, Bruno S, Manns MP Sulkowski MS, Jacobson IM, Reddy KR, Goodman ZD, Boparai N, DiNubile MJ, Sniukiene V, Brass CA, Albrecht JK, Bronowicki JP; SPRINT-2 Investigators: Boceprevir for untreated chronic HCV genotype 1 infection. N Engl J Med 2011;364:1195-1206.

8 Afdhal N, Reddy KR, Nelson DR, et al: Ledipasvir and sofosbuvir for previously treated HCV genotype 1 infection. N Engl J Med 2014;370:1483-1493.

$\checkmark$ Afdhal N, Zeuzem S, Kwo P, et al: Ledipasvir and sofosbuvir for untreated HCV genotype 1 infection. N Engl J Med 2014;370:1889-1898.

10 Kowdley KV, Gordon SC, Reddy KR, et al: Ledipasvir and sofosbuvir for 8 or 12 weeks for chronic HCV without cirrhosis. N Engl J Med 2014;370:1879-1888.

11 Lawitz E, Sulkowski MS, Ghalib R, et al: Simeprevir plus sofosbuvir, with or without ribavirin, to treat chronic infection with hepatitis $\mathrm{C}$ virus genotype 1 in non-responders to pegylated interferon and ribavirin and treatment-naive patients: the COSMOS randomised study. Lancet 2014;384:1756-1765.

12 Sulkowski MS, Gardiner DF, Rodriguez-Torres M, et al: Daclatasvir plus sofosbuvir for previously treated or untreated chronic HCV infection. N Engl J Med 2014; 370:211-221.

13 Feld JJ, Kowdley KV, Coakley E, Sigal S, Nelson DR, Crawford D, Weiland O, Aguilar H, Xiong J, PilotMatias T, DaSilva-Tillmann B, Larsen L, Podsadecki T, Bernstein B: Treatment of HCV with abt-450/ r-ombitasvir and dasabuvir with ribavirin. N Engl J Med 2014;370:1594-1603.

14 Ferenci P, Bernstein D, Lalezari J, et al: Abt-450/r-ombitasvir and dasabuvir with or without ribavirin for HCV. N Engl J Med 2014;370:1983-1992.

15 Poordad F, Hezode C, Trinh R, Kowdley KV, Zeuzem S, Agarwal K, Shiffman ML, Wedemeyer H, Berg T, Yoshida EM, Forns X, Lovell SS, Da Silva-Tillmann B, Collins CA, Campbell AL, Podsadecki T, Bernstein B: Abt-450/r-ombitasvir and dasabuvir with ribavirin for hepatitis C with cirrhosis. N Engl J Med 2014;370: 1973-1982.

16 Zeuzem S, Jacobson IM, Baykal T, Marinho RT, Poordad F, Bourliere M, Sulkowski MS, Wedemeyer H, Tam E, Desmond P, Jensen DM, Di Bisceglie AM, Varunok P, Hassanein T, Xiong J, Pilot-Matias T, DaSilva-Tillmann B, Larsen L, Podsadecki T, Bernstein B: Retreatment of HCV with abt-450/r-ombitasvir and dasabuvir with ribavirin. N Engl J Med 2014;370:16041614.

17 Friedrich-Rust M, Ong MF, Martens S, Sarrazin C, Bojunga J, Zeuzem S, Herrmann E: Performance of transient elastography for the staging of liver fibrosis: meta-analysis. Gastroenterology 2008;134:960-974.

18 Friedrich-Rust M, Nierhoff J, Lupsor M, Sporea I, Fierbinteanu-Braticevici C, Strobel D, Takahashi H, Yoneda M, Suda T, Zeuzem S, Herrmann E: Performance of acoustic radiation force impulse imaging for the staging of liver fibrosis: a pooled meta-analysis. J Viral Hepat 2012;19:e212-219.
19 Castera L, Sebastiani G, Le Bail B, de Ledinghen V, Couzigou P, Alberti A: Prospective comparison of two algorithms combining non-invasive methods for staging liver fibrosis in chronic hepatitis C. J Hepatol 2010; 52:191-198.

20 European Association for the Study of the Liver: EASL recommendations on treatment of hepatitis C 2015. J Hepatol 2015;63:199-236.

21 Sarrazin C, Berg T, Buggisch P, Dollinger MM, Hinrichsen $\mathrm{H}$, Hofer H, Huppe D, Manns MP, Mauss S, Petersen J, Simon KG, van Thiel I, Wedemeyer H, Zeuzem S: S3 guideline hepatitis C addendum (article in German). Z Gastroenterol 2015;53:320-334.

22 Welker M, Luhne S, Lange C, Vermehren J, Farnik H, Herrmann E, Welzel T, Zeuzem S, Sarrazin C: Lactic acidosis in patients with hepatitis $\mathrm{C}$ virus cirrhosis and combined ribavirin/sofosbuvir treatment. J Hepatol 2015;DOI: 10.1016/j.jhep.2015.11.034.

23 Charlton MR, Samuel D, Manns MP, Forns X, Flamm SL, Reddy KR, Denning J, Arterburn S, Brandt-Sarif TS, Pang P, McHutchison JG, Afdhal NH, Gane E, Mutimer D, Everson GT: Ledipasvir/sofosbuvir with ribavirin is safe in $>600$ decompensated and post liver transplantation patients with $\mathrm{HCV}$ infection: an integrated safety analysis of the solar 1 and solar 2 trials. Gastroenterology 2015;148:S971-S971.

24 Poordad F, Schiff E, Vierling J, Landis C, Fontana R, Yang R, McPhee F, Hughes E, Noviello S, Swenson E: Daclatasvir, sofosbuvir, and ribavirin combination for HCV patients with advanced cirrhosis or post-transplant recurrence: phase 3 ALLY-1 study. J Viral Hepat 2015;22:30-31.

25 Lawitz E, Matusow G, DeJesus E, Yoshida E, Felizarta F, Ghalib R, Godofsky E, Herring R, Poleynard G, Sheikh A, Tobias H, Kugelmas M, Kalmeijer R, Peeters M, Lenz O, Fevery B, De La Rosa G, Scott J, Sinha R, Witek J: A phase 3, open-label, single-arm study to evaluate the efficacy and safety of 12 weeks of simeprevir (SMV) plus sofosbuvir (SOF) in treatment-naive or -experienced patients with chronic HCV genotype 1 infection and cirrhosis: OPTIMIST-2. J Hepatol 2015;62:S264-S265.

26 Osinusi A, Townsend K, Kohli A, et al: Virologic response following combined ledipasvir and sofosbuvir administration in patients with HCV genotype 1 and HIV co-infection. JAMA 2015;313:1232-1239.

27 Sulkowski MS, Eron JJ, Wyles D, et al: Ombitasvir, paritaprevir co-dosed with ritonavir, dasabuvir, and ribavirin for hepatitis $\mathrm{C}$ in patients co-infected with HIV-1: a randomized trial. JAMA 2015;313:1223-1231.

28 Naggie S, Cooper C, Saag M, et al.; ION-4 Investigators: Ledipasvir and sofosbuvir for HCV in patients coinfected with HIV-1. N Engl J Med 2015;373:705713.

29 Wyles DL, Ruane PJ, Sulkowski MS, et al: Daclatasvir plus sofosbuvir for $\mathrm{HCV}$ in patients coinfected with HIV-1. N Engl J Med 2015;373:714-725.

30 Welker M-W, Zeuzem S: Pre- and post-transplant antiviral therapy (HBV, HCV). Visc Med 2016;32:区-区.

31 Reddy KR, Bourliere M, Sulkowski M, et al: Ledipasvir and sofosbuvir in patients with genotype 1 hepatitis $\mathrm{C}$ virus infection and compensated cirrhosis: an integrated safety and efficacy analysis. Hepatology 2015; 62:79-86.

32 Bourliere M, Bronowicki JP, de Ledinghen V, et al: Ledipasvir-sofosbuvir with or without ribavirin to treat patients with HCV genotype 1 infection and cirrhosis non-responsive to previous protease-inhibitor therapy: a randomised, double-blind, phase 2 trial (SIRIUS). Lancet Infect Dis 2015;15:397-404.
3 Feld JJ, Moreno C, Trinh R, Tam E, Bourgeois S, Hors mans Y, Elkhashab M, Bernstein DE, Younes Z, Reindollar RW, Larsen L, Fu B, Howieson K, Polepally AR, Pangerl A, Shulman NS, Poordad F: Sustained virologic response of $100 \%$ in HCV genotype $1 \mathrm{~b}$ patients with cirrhosis receiving ombitasvir/paritaprevir/ $\mathrm{r}$ and dasabuvir for 12 weeks. J Hepatol 2016;64:301-307.

34 Welzel TM, Herzer K, Ferenci P, Petersen J, Gschwantler M, Cornberg M, Berg T, Spengler U, Weiland O, Van der Valk M, Klinker H, Rockstroh J, Ingiliz P, Peck-Radosavljevic M, Jimenez-Exposito MJ, Zeuzem S: Daclatasvir plus sofosbuvir with or without ribavirin for the treatment of $\mathrm{HCV}$ in patients with severe liver disease: interim results of a compassionate use program. J Hepatol 2015;62:S619-S620.

35 Lawitz E, Mangia A, Wyles D, et al: Sofosbuvir for previously untreated chronic hepatitis $\mathrm{C}$ infection. $\mathrm{N}$ Engl J Med 2013;368:1878-1887.

36 Jacobson IM, Gordon SC, Kowdley KV, et al: Sofosbuvir for hepatitis $\mathrm{C}$ genotype 2 or 3 in patients without treatment options. N Engl J Med 2013;368:1867-1877.

37 Ho S, Monto A, Peyton A, Kaplan D, Byrne S, Moon S, Zhu Y, Seyedkazemi S, Rossaro L, Brainard D, Guyer W, Shaikh O, Fuchs M, Morgan T: Twelve weeks of sofosbuvir plus ribavirin is effective for treatment of genotype $2 \mathrm{HCV}$ in difficult to treat U.S. veterans with cirrhosis - results of the VALOR-HCV study. Hepatology 2015;62(suppl 1):718A.

38 Welzel T, Nelson D, Morelli G, Di Bisceglie A, Reddy K, Kuo A, Lim J, Darling J, Pockros P, Galati J, Frazier L, Alqahtani S, Sulkowski M, Fried M, Zeuzem S: Safety and efficacy of sofosbuvir and ribavirin for the treatment of HCV genotype 2 and 3: results of the HCV-TARGET study. Hepatology 2015;62(suppl 1): 727A.

39 Foster GR, Pianko S, Brown A, Forton D, Nahass RG, George J, Barnes E, Brainard DM, Massetto B, Lin M, Han B, McHutchison JG, Subramanian GM, Cooper C, Agarwal K: Efficacy of sofosbuvir plus ribavirin with or without peginterferon-alfa in patients with hepatitis $\mathrm{C}$ virus genotype 3 infection and treatment-experienced patients with cirrhosis and hepatitis $\mathrm{C}$ virus genotype 2 infection. Gastroenterology 2015;149:1462-1470.

40 Hedskog C, Doehle B, Chodavarapu K, Gontcharova V, Crespo Garcia J, De Knegt R, Drenth JP, McHutchison JG, Brainard D, Stamm LM, Miller MD, Svarovskaia E, Mo H: Characterization of hepatitis $\mathrm{C}$ virus intergenotypic recombinant strains and associated virological response to sofosbuvir/ribavirin. Hepatology 2015;61:471-480.

41 Foster GR, Afdhal N, Roberts SK, et al: Sofosbuvir and velpatasvir for HCV genotype 2 and 3 infection. N Engl J Med 2015;373:2608-2617.

42 Gao M, Nettles RE, Belema M, Snyder LB, Nguyen VN, Fridell RA, Serrano-Wu MH, Langley DR, Sun JH, O'Boyle DR 2nd, Lemm JA, Wang C, Knipe JO, Chien C, Colonno RJ, Grasela DM, Meanwell NA, Hamann LG: Chemical genetics strategy identifies an $\mathrm{HCV}$ NS5A inhibitor with a potent clinical effect. Nature 2010;465:96-100.

43 Li YP, Ramirez S, Humes D, Jensen SB, Gottwein JM, Bukh J: Differential sensitivity of 5'UTR-NS5A recombinants of hepatitis $C$ virus genotypes 1-6 to protease and NS5A inhibitors. Gastroenterology 2014; 146:812821.e814.

44 Zeuzem S, Dusheiko GM, Salupere R, Mangia A, Flisiak R, Hyland RH, Illeperuma A, Svarovskaia E, Brainard DM, Symonds WT, Subramanian GM, McHutchison JG, Weiland O, Reesink HW, Ferenci P, Hezode C, Esteban R: Sofosbuvir and ribavirin in HCV genotypes 2 and 3. N Engl J Med 2014;370:1993-2001. 
45 Nelson DR, Cooper JN, Lalezari JP, et al: All-oral 12 week treatment with daclatasvir plus sofosbuvir in patients with hepatitis $C$ virus genotype 3 infection: ALLY-3 phase III study. Hepatology 2015;61:11271135.

46 Leroy V, Angus P, Bronowicki J, Dore G, Hézode, C, Piano S, Pol S, Stuart K, Tse E, McPhee F, Bohre R, Jimenez-Esposito M, Thompson A: All-oral treatment with daclatasvir plus sofosbuvir plus ribavirin for 12 or 16 weeks in HCV genotype 3-infected patients with advanced fibrosis or cirrhosis: the ALLY-3+ phase 3 study. The Liver Meeting 2015. San Francisco, CA, 13-17 November 2015, Oral LB-3, 2015.

47 Welzel T, Petersen J, Ferenci P, Gschwantler M, Herzer K, Cornberg M, Schott E, Berg T, Spengler U, Weiland $\mathrm{O}$, van der Falk M, Geier A, Rockstroh J, PeckRadosavljevic M, Zhao Y, Jimenez Esposito M, Zeuzem S: Safety and efficacy of daclatasvir plus sofosbuvir with or without ribavirin for the treatment of chronic HCV genotype 3 infection: interim results of a multicenter European compassionate use program. Hepatology 2015;62:62A.

48 Kohli A, Kapoor R, Sims Z, Nelson A, Sidharthan S Lam B, Silk R, Kotb C, Gross C, Teferi G, Sugarman K, Pang PS, Osinusi A, Polis MA, Rustgi V, Masur H, Kottilil S: Ledipasvir and sofosbuvir for hepatitis $C$ genotype 4: a proof-of-concept, single-centre, open-label phase 2a cohort study. Lancet Infect Dis 2015;15: 1049-1054.
49 Abergel A, Loustaud-Ratti V, Metivier S, Jiang D, Kersey K, Knox SJ, Pang PS, Samuel D, Asselah T: Ledipasvir/sofosbuvir treatment results in high SVR rates in patients with chronic genotype 4 and $5 \mathrm{hcv}$ infection. Journal of Hepatology 2015;62:S219-S220.

50 Asselah TH, Qaqish TI, Feld RB, et al: Efficacy and safety of ombitasvir/paritaprevir/ritonavir co-administered with ribavirin in adults with genotype 4 chronic hepatitis $\mathrm{C}$ infection and cirrhosis (Agate-I). Hepatology 2015;62:119A.

51 El Raziky M, Gamil M, Hammad R, Saad Hashem M, Khairy M, Elsharkawy A, Gomaa A, Keim S, Van Dooren G, Ryan R, DeMasi R, Londjon-Domanec I, Hassany M, Doss W, Waked I: Treatment of hepatitis C genotype 4 patients with simeprevir and sofosbuvir: preliminary results from a phase IIa, partially randomised, open-label trial conducted in Egypt (OSIRIS). Hepatology 2015;62:145A.

52 Gane E, Hyland R, An D, Svarovskaia E, Pang P, Symonds W, McHutchison J, Stedman C: High efficacy of LDV/SOF regimens for 12 weeks for patients with HCV genotype 3 or 6 infection. Hepatology 2014;60: LB-11.
53 Terrault N, Zeuzem S, Di Bisceglie A, Lim J, Pockros P, Frazier L, Kuo A, Lok A, Shiffman M, Ben Ari Z, Stewart T, Sulkowski M, Fried M, Nelson D: Treatment outcomes with 8,12 and 24 week regimens of ledipasvir/sofosbuvir for the treatment of hepatitis $\mathrm{C}$ infection: analysis of a multicenter prospective, observational study. Hepatology 2015;62:67A.

54 Morgan TR, Ghany MG, Kim HY, Snow KK, Shiffman ML, De Santo JL, Lee WM, Di Bisceglie AM, Bonkovsky HL, Dienstag JL, Morishima C, Lindsay KL, Lok AS: Outcome of sustained virological responders with histologically advanced chronic hepatitis C. Hepatology 2010;52:833-844

55 Crissien AM, Minteer WB, Pan JJ, Frenette CT, Pockros PJ: Regression of advanced fibrosis or cirrhosis measured by elastography in patients with chronic hepatitis $\mathrm{C}$ who achieve sustained virologic response after treatment for HCV. Hepatology 2015;62:264A$265 \mathrm{~A}$.

56 de Franchis R: Expanding consensus in portal hypertension: report of the BAVENO VI consensus workshop: stratifying risk and individualizing care for portal hypertension. J Hepatol 2015;63:743-752.

57 Mandorfer MK, Kozbial K, Schwabl P, Freissmuth C, Schwarzer R, Stern R, Bota S, Reiberger T, Stättermayer A, Sieghart W, Beinhardt S, Trauner M, Hofer H, Ferlitsch A, Ferenci P, Peck-Radosavljevic M: Viral suppression with IFN-free therapies ameliorates portal hypertension in patients with hepatitis C-related cirrhosis. Hepatology 2015;62:574A 